\title{
Double trouble from space
}

This February saw two close calls with cosmic disaster. On 15 February 2013, a 45-metre asteroid streaked past only about 27,000 km from Earth - inside the ring of geosynchronous satellites, and less than one-tenth of the distance to the Moon. Just hours earlier, a 17-metre-wide meteoroid had burned through the atmosphere at $65,000 \mathrm{~km} \mathrm{~h}^{-1}$ and exploded over Russia, creating a shock wave that blew out glass from thousands of buildings and left a thousand people in need of medical care.

The two rocks came from different places, making their arrival on the same day a coincidence. Neither of them came close to causing catastrophic damage - the asteroid that killed the dinosaurs, for comparison, was about $10 \mathrm{~km}$ across. But the double scare has reawakened interest in apocalypsescale collisions, which several organizations are aiming to predict and avoid.

The larger rock, called $2012 \mathrm{DA}_{14}$, was first spotted a year ago. Astronomers were able to plot its trajectory and knew that this 130,000-tonne missile would miss the Earth - but would also be our closest known encounter with a rock of this size since sky surveys began in the 1990s. Were it to hit, an asteroid like this could destroy a city twice the size of London. In 1908, an asteroid the same order of magnitude in

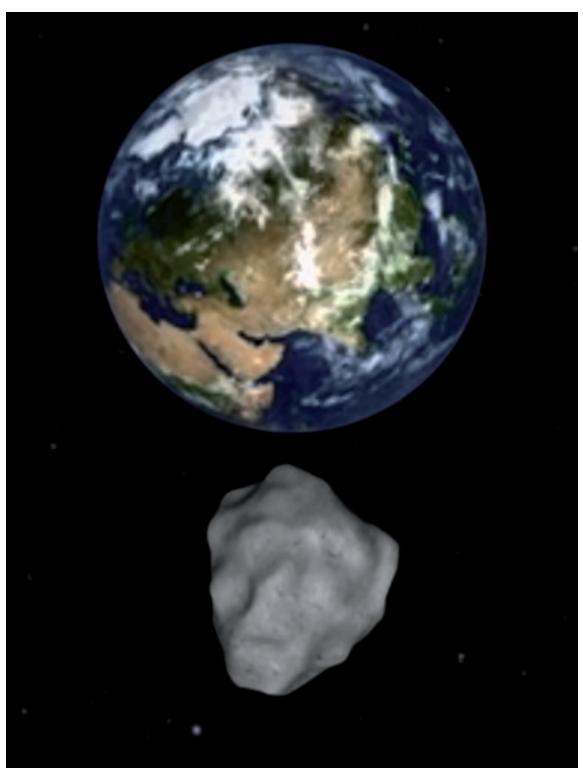

diameter exploded over Siberia, flattening 2,200 square kilometres of trees near the Tunguska River. Fly-bys of rocks of this size are expected every 40 years or so, with a collision once every 1,200 years.

The meteoroid that exploded over Russia was the largest object known to hit the Earth since the Tunguska event. The blow-up of this 10,000-tonne rock in the atmosphere released 500 kilotonnes of energy over a 32.5-second burn-up. Despite its size, no one saw it coming until it was a visible streak in the sky over Chelyabinsk. It probably came from the asteroid belt between Mars and Jupiter (http://arxiv. org/abs/1302.5377). An encounter with an object of this size is expected to occur about once every 100 years.

NASA's Near Earth Object Program has so far discovered 9,738 chunks of ice or rock that will probably pass close to Earth, of which 863 are more than a kilometre wide and 1,379 are labelled as 'potentially hazardous' to the planet. The most worrying of these is the 120-metre asteroid $2007 \mathrm{VK}_{184}$, which is thought to have a 1 in 1,820 chance of hitting us in 2048. But there could be other dangers: it is estimated that fewer than $1 \%$ of asteroids larger than $\mathrm{DA}_{14}$ have been identified and tracked. A group of ex-astronauts and scientists, called the B612 Foundation (named after the asteroid that Le Petit Prince made his home in the famous 1943 French novella), is aiming to do a better job at cataloguing threats - by launching their own asteroidspotting satellite by 2018 .

Nicola Jones is a freelance journalist based in Pemberton, British Columbia, Canada.

\section{The journalist's take}

Take a record-breaking near-miss asteroid, add videos of a meteor impact and top with a heightened public appetite for disaster in the aftermath of the 'Armageddon 2012' stories, and you have a winning recipe for a media blitz.

The arc of this story starts in February 2012, with the discovery of the $\mathrm{DA}_{14}$ asteroid by the Astronomical Observatory in Mallorca, Spain. More stories name-checking $\mathrm{DA}_{14}$ trickled out in December 2012, when the end of a 5,125-year-long cycle in the Mayan calendar spurred panic about the imminent end of the world. Journalists of course discounted the notion, but used it as an excuse to look at what Armageddon-style disasters might actually happen in the not-too-distant future. Then, just before 15 February, 'curtain-raiser' stories were common, reminding readers about the upcoming asteroid pass and giving practical details about whether it could be spotted by amateur astronomers and what researchers might learn from the fly-by.

Chances are that the pass itself would have been covered very briefly by most, with extended coverage only in more specialist publications. But the Chelyabinsk meteor changed that, with its visceral eye-witness reports and YouTube videos. The story became greater than the sum of its parts.

The life cycle of breaking news stories, like this one, is different from that resulting from research papers. Journalists respond to breaking news within minutes of the event occurring, initially quoting the easiest sources such as authorities putting out press statements or local experts with any link, no matter how tenuous, to the subject matter. Longer, more considered stories follow. As the ocean of stories swells, reporters look for more angles to keep riding the wave of reader interest. Thus, you often get fun peripheral pieces such as National Geographic's “The True Story of History's Only Known Meteorite Victim" (http://go.nature.com/ oJZuCD). Research papers, by contrast, are usually press released under embargo, giving journalists up to a week before publication to do thorough reporting on a one-shot story, and to choose sources and story angles in advance.

Chasing 'real world' news can be more thrilling for journalists, and often comes with a wider readership. A meteorite exploding mid-air carries far more immediacy than a paper about the hypothetical risks of impacts. Nothing gets a reporter's blood pumping like a natural disaster - except, perhaps, a tight deadline. 